\title{
O DISCURSO TELEVISIVO ACERCA DE NEYMAR JÚNIOR E O FUTEBOL BRASILEIRO
}

\author{
Nayla Pereira dos Santos \\ Cleide Lima Chaves**
}

RESUMO: O presente artigo busca compreender o discurso contido em uma reportagem sobre o jogador da seleção brasileira, Neymar Júnior e de que forma ele está evidenciado na construção narrativa. Discute-se como a identidade nacional é construída e como o futebol tem sido elemento fundamental na construção da identidade nacional brasileira. Por fim, analisa-se, a luz da teoria de análise do discurso proposta por Charaudeau (2008), a reportagem sobre o atacante, exibida no Jornal Nacional da Rede Globo de televisão. A reportagem faz parte de uma série intitulada "Perfis", transmitida em agosto de 2018, que buscava apresentar os jogadores da seleção brasileira que disputaram a Copa do Mundo de 2018 na Rússia. O objetivo é desvelar as estratégias utilizadas pelo autor no texto na construção de um discurso acerca do atacante. Conclui-se que o discurso construído na reportagem relaciona a imagem do jogador à de um herói nacional.

PALAVRAS-CHAVE: Discurso; Futebol; Identidade nacional; Jornalismo; Narrativa.

\section{Introdução}

As narrativas jornalísticas associadas ao esporte têm características próprias. São narrativas, na maioria das vezes leves e dinâmicas e, quando tratam do futebol, alguns outros elementos são comumente encontrados, como a associação do esporte com a identidade nacional e a relevância dele no Brasil.

\footnotetext{
* Mestranda em Letras: Cultura, Educação e Linguagens pela Universidade Estadual do Sudoeste da Bahia (Uesb).

** Professora titular da Universidade Estadual do Sudoeste da Bahia (Uesb). Doutora em História Social pela Universidade Federal do Rio de Janeiro (UFRJ).
} 
O presente artigo busca discutir como se dão as narrativas jornalísticas na contemporaneidade e de que forma diferentes discursos estão imbricados nestas. O objetivo é verificar o discurso produzido em uma reportagem jornalística esportiva exibida no Jornal Nacional e se esse discurso contribui para a construção da figura de um 'herói' nacional.

O estudo analisa uma reportagem com onze minutos de duração, parte de uma série de reportagens sobre os jogadores da seleção brasileira que disputaram a Copa do Mundo na Rússia em 2018. A matéria trata sobre o atacante Neymar Júnior e foi escolhida, dentre as outras 22 reportagens da série, por ser considerado por muitos - e na maioria das vezes pela mídia - como o grande craque do time e o melhor jogador da seleção.

A discussão aqui aborda as narrativas jornalísticas na contemporaneidade e a forma como elas são construídas. Posteriormente é tratada a questão da identidade nacional e o como o futebol permeia essa ideia de nação e por fim analisaremos a reportagem sobre o jogador Neymar Júnior.

Compreender que as narrativas jornalísticas têm objetivos específicos por trás de todo conteúdo é também entender que elas são dotadas de um discurso. É nesse ponto que se torna interessante compreender Charaudeau (2008), pois ele entende que o discurso está inserido no texto e os dois termos não são sinônimos como muitos acreditam. O discurso, portanto, seria a ideia contida no texto, as opiniões e impressões que carrega, o que ele 'diz' sobre determinada coisa. O discurso em uma reportagem jornalística estaria carregado dessa subjetividade, razão e emoção do jornalista que, antes de tudo, é um ser dotado de sentimentos e intenções.

A análise a seguir tem como base metodológica a concepção desse autor que trabalha com quatro tipos de sujeitos presentes no ato de linguagem: sujeito destinatário (TUd), sujeito interpretante (TUi), sujeito enunciador (EUe) e sujeito comunicante (EUc). No que diz respeito ao discurso das mídias, objeto de estudo desse trabalho, o TUd e o TUi estão no campo da recepção, já o EUe e o EUc no campo de produção.

Segundo o autor, o EUc (sujeito comunicante) é um sujeito agente e responsável pela organização do ato linguagem, já o EUe (sujeito enunciador) é um sujeito realizado e 
instituído na fala, este é quem produz um efeito de discurso sobre o interpretante. Já o TUd (sujeito destinatário) é um sujeito de fala que é instituído pelo EU e depende dele. O TUi (sujeito interpretante) é um sujeito que age de forma independente do EU e estabelece a si mesmo como sendo responsável pela interpretação que produz (CHARAUDEAU, 2008, p. 47).

Charaudeau (Ibidem) defende ainda que escolhas são feitas pelo sujeito falante, no campo da produção que buscam o objetivo de alcançar o destinatário ideal, o que o autor vai designar de visadas: "as visadas devem ser consideradas do ponto de vista da instância de produção que tem em perspectiva um sujeito destinatário ideal, mas evidentemente elas devem ser reconhecidas como tais pela instância de recepção" (CHARAUDEAU, 2004, n.p. ).

Por isso, para compreender um discurso é necessário considerar as condições de produção desse discurso, quem é o sujeito falante, em qual contexto ele está inserido e quais os saberes mobilizados pelo sujeito falante ao transmitir a mensagem. Com isso, o contrato de comunicação é estabelecido e só a partir dele que o ato de comunicação é reconhecido como válido.

Sobre as concepções apresentadas, Avrella e Carvalho (2018) afirmam que:

Avançando nessa perspectiva, Charaudeau. (2006) destaca que a finalidade do contrato de comunicação midiática está numa tensão entre duas visadas: a visada de informação. (fazer saber) e a visada de captação. (fazer sentir). A primeira tende a produzir um objeto de saber segundo uma lógica cívica: informar o cidadão. A outra tende a produzir um objeto de consumo segundo uma lógica comercial: captar as massas para sobreviver à concorrência. Segundo Charaudeau, em relação à visada de informação, as mídias estão sempre em confronto permanente com um problema de credibilidade, "porque baseiam sua legitimidade no 'fazer crer que o que é dito é verdadeiro"' (CHARAUDEAU, 2006, p. 90). O autor complementa destacando que as mídias estão engajadas num jogo de verdade, que consiste em corresponder aos diferentes imaginários sociais que as questionam. (AVRELLA; CARVALHO, 2018, p. 132) 
Dentro desse "jogo de verdade”, a mídia trabalha com uma dinâmica que produz símbolos e significados e que transmite a esse receptor uma ideia do lugar onde ele está inserido. Kellner (2006) defende, portanto, que o consumo inconsciente desses produtos midiáticos seria um fator alienante do potencial criador e da imaginação.

Podemos admitir que o relato de determinado acontecimento, ou seja, o relato de uma mudança em um estado de coisas constitui-se uma narrativa e sendo esse acontecimento de interesse público, surge então uma narrativa jornalística. Como abordam Sodré e Ferrari (1986):

Quando o jornal diário noticia um fato qualquer, como um atropelamento, já traz aí, em germe, uma narrativa. O desdobramento das clássicas perguntas a que a notícia pretende responder. (quem, o quê, como, quando, onde, por quê) constituirá de pleno direito uma narrativa, não mais regida pelo imaginário, como na literatura de ficção, mas pela realidade factual do dia-a-dia, pelos pontos rítmicos do cotidiano que, discursivamente trabalhados, tornam-se reportagem. (SODRÉ; FERRARI, 1986, p. 11)

A construção desta narrativa por parte do jornalista perpassa diversas questões que vão desde as percepções pessoais até as influências do meio de comunicação no qual o jornalista esteja inserido. Primeiramente, o jornalista precisa decidir o que, no meio do volume informativo que recebe diariamente, vai se tornar uma notícia, ou seja, qual dos acontecimentos que chegaram à redação se transformará em uma narrativa jornalística. Até porque, segundo Beltrão (1960) uma das características do jornalismo é a variedade:

Com efeito, dissemos que o jornalismo era a informação de fatos correntes, de acontecimentos registrados em qualquer setor da vida social, em qualquer parte do universo, em qualquer domínio das ciências, das artes, da natureza e do espírito, que sejam capazes de despertar os interesses dos homens reunidos em sociedade. E neste primeiro enunciado estão duas das características do jornalismo: - a atualidade e a variedade. (BELTRÃO, 1960, p. 38)

Beltrão (1960) explica que uma das funções do jornalista é analisar os fatos antes de torná-los conhecidos ao público, fazendo um julgamento da relevância de cada um deles e 
condensando os acontecimentos, desta forma, cumprindo sua função de interpretar. Desde o momento em que o jornalista escolhe o que deve ou não ser noticiado, começam as influências do profissional na narrativa jornalística.

A dificuldade em se admitir que as notícias jornalísticas são parciais tem uma configuração parecida a que afirma que reportagens não são narrativas. Motta (2013) em uma entrevista ${ }^{34}$ opinou que:

Eu acho que essa preocupação cada vez maior com a narrativa está gerando um questionamento do jornalismo. Ela é hoje quase uma técnica para você fazer uma crítica do jornalismo. Crítica em que sentido? Você mostrar que o jornalismo é superficial na maneira que ele cobre os fatos. Ele fica na superfície, tentando ser objetivo, enquanto na verdade está carregado de subjetividade. Então, por que não assumir essa subjetividade e contar os fatos desde um ponto de vista narrativo? Aí, você começa a mostrar que as pessoas são compostas de razão e de emoção. Assim que é o mundo humano e assim que somos nós. Então, contando narrativamente, você deixa essa emoção entrar no seu texto. (MOTTA, 2013)

Então é possível afirmar que não existe problema no fato do jornalista utilizar a narração para construir uma notícia. O mais importante então, é que haja uma concordância de que se o relato de um acontecimento se constitui uma narrativa ele está então, dotado de subjetividade e da razão e emoção inerente ao jornalista que carrega consigo preceitos e valores que foram construídos durante toda a sua vida. Essas características que lhe são próprias encontram lugar em seu texto, seja na decisão do que publicar, na escolha das palavras, ou na construção narrativa propriamente dita.

É interessante ressaltar que, além das impressões e opiniões do jornalista e do meio de comunicação no qual ele está inserido, ficam implícitas no texto as narrativas jornalísticas esportivas, principalmente relacionadas ao futebol, tendem a trazer um apelo muito forte em relação a identidade nacional e como o futebol tem uma larga contribuição na

${ }^{34}$ Disponível em: < http://site.ufsm.br/noticias/exibir/9266>. Acesso em: 20 de dezembro de 2018. 
construção dessa identidade. Por isso se faz necessário compreender de que forma a identidade, dita como nacional, é construída socialmente.

O futebol, mais do que qualquer outro esporte, está ligado diretamente à identidade nacional brasileira. Jargões como "Brasil, país do futebol” são constantemente ecoados na maioria dos espaços sociais e reforçados nos meios de comunicação principalmente.

A denominada paixão nacional pelo esporte não emergiu de forma aleatória e muito menos despropositadamente. A construção de um discurso do Brasil atrelado a prática do futebol surgiu com intenções muito específicas, em determinado momento da história, que foi a Era Vargas (1930-1945) e foi se perpetuando com o passar dos anos. A criação de heróis relacionados ao esporte vem colaborar com a reafirmação dessa identidade.

Essa identidade nacional não é construída apenas da relação do indivíduo com os demais, formando uma teia de significações que, por convenção, se entende como identidade nacional. É um processo bem mais amplo e que envolve diversos aspectos.

Stuart Hall (2015) defende que a ideia de que a nação que temos conhecimento nada mais é do que uma cultura imaginada, algo que foi perpassado durante séculos e adotamos sem maiores questionamentos.

$\mathrm{O}$ argumento que estarei considerando aqui é que, na verdade, as identidades nacionais não são coisas com as quais nós nascemos, mas são formadas e transformadas no interior da representação[...]. Segue-se que a nação não é apenas uma entidade política, mas algo que produz sentidos - um sistema de representação cultural. As pessoas não são apenas cidadãos legais de uma nação; elas participam da ideia da nação tal como representada em sua cultura nacional". (HALL, 2015, p. 30)

Para se chegar a ideia de identidade nacional que adotamos na atualidade, Hall (ibidem) aponta cinco influências que recebemos desde crianças e que constroem em nós essa ideia de nação. O primeiro fator é a narrativa de nação que comumente é contada na literatura nacional, mídia e cultura popular. Por se tratar do objeto de análise deste trabalho tomo como exemplo principal os meios de comunicação, pois desde as matérias jornalísticas, passando pelas propagandas é comum nos depararmos com narrativas ufanistas. 
Durante os Jogos Olímpicos de 2016, por exemplo, propagandas de marcas famosas, do governo brasileiro e de emissoras de televisão evidenciavam esse discurso. Na peça publicitária do governo nacional a frase estampada durante as propagandas era "\#somostodosbrasil". Já a propaganda da Rede Globo de Televisão trazia a inscrição "Somos Todos Olímpicos". Essas frases trazem um apelo ao telespectador em torno da ideia de nação e em torno dos Jogos Olímpicos e da importância de valorizar o evento que, em 2016, aconteceu no Brasil.

O segundo elemento apresentado por Hall é que existe uma ênfase nas origens e na tradição, em que a identidade nacional é representada como primordial

[...] 'está lá, na verdadeira natureza das coisas', algumas vezes adormecida, mas sempre pronta para ser 'acordada' de sua 'longa, persistente e misteriosa sonolência', para reassumir sua inquebrantável existência. (GELNNER, 1963, p. 48). Os elementos essenciais do caráter nacional permanecem imutáveis, apesar de todas as vicissitudes da história. Está lá desde o nascimento, unificado e contínuo, 'imutável' ao longo de todas as mudanças, eterno. (HALL, 2015, p. 32)

Essa ideia de nação "antes de todas as coisas” é praticamente despercebida, por ela estar no âmbito das divagações e implícita nos discursos diários. É um conceito impregnado em pensamentos e em produtos culturais criados pelo próprio indivíduo durante a vida. É uma ideia em que se acredita, sem muitos questionamentos.

A terceira estratégia discursiva apresentada pelo autor diz respeito ao que Hobsbawm e Ranger (1983) chamam de 'invenção da tradição'. São tradições que costumam parecer, ou mesmo alegam ser bastante antigas e na realidade são recentes ou algumas vezes inventadas:

'Tradição Inventada' [significa] um conjunto de práticas, [...] de natureza ritual ou simbólica, que buscam inculcar certos valores e normas de comportamentos através da repetição, a qual, automaticamente, implica continuidade com um passado histórico adequado. Por exemplo, 'nada parece ser mais antigo e vinculado ao passado imemorial do que a pompa que rodeia a monarquia britânica e suas 
manifestações cerimoniais públicas. No entanto... na sua forma moderna, ela é produto do final do século XIX e XX. (HOBSBAWM; RANGER, 1983, p. 1 apud HALL, 2015, p. 32)

Trazendo para a cultura brasileira, o mote "Brasil, país do futebol" foi construído a partir das vitórias conquistadas pela seleção brasileira em Copas do Mundo, ou mesmo como forma de reafirmação da identidade nacional em determinado momento histórico do que propriamente nos anos em que o esporte tem sido praticado no país. A primeira edição da Copa do Mundo aconteceu em 1930, há 88 anos, e o time de futebol brasileiro documentado e mais antigo é o Sport Clube Rio Grande, clube do Rio Grande do Sul fundado em 1890, com 119 anos de história.

O quarto exemplo de narrativa da cultura nacional apresentado pelo autor é a do mito fundacional: "uma história que localiza a origem da nação, do povo e de seu caráter nacional num passado tão distante que eles se perdem nas brumas do tempo, não do tempo 'real', mas de um tempo 'mítico"' (HALL, 2015, p. 33).

Esse mito fundacional no Brasil se caracteriza, entre outras coisas, pelo grito de Independência de Dom Pedro às margens do Rio Ipiranga, história que é sempre trazida à tona nas escolas, por exemplo, e no hino nacional, entoado sempre em momentos como jogos de futebol, formaturas e outros eventos.

A quinta e última constatação trazida por Hall (2015) é a de que a identidade nacional é muitas vezes simbolicamente baseada na ideia um povo "original": "Mas, nas realidades do desenvolvimento nacional, é raramente esse povo [folk] primordial que persiste ou que exercita o poder" (idem, p. 33).

Esses elementos, somados, colaboram na construção dessa ideia de identidade nacional que permeia a sociedade. Mas o autor ressalta que essas identidades tentam se "equilibrar" entre passado e futuro:

O discurso da cultura nacional não é, assim, tão moderno como aparenta ser. Ele constrói identidades que são colocadas, de modo ambíguo, entre o passado e o futuro. Ele se equilibra entre a tentação por retornar a glórias passadas e o impulso por avançar ainda mais 
em direção à modernidade. As culturas nacionais são tentadas, algumas vezes, a se voltar para o passado, a recuar defensivamente para aquele 'tempo perdido', quando a nação era 'grande'; são tentadas a restaurar as identidades passadas. Esse constitui o elemento regressivo, anacrônico, da história da cultura nacional. (HALL, 2015, p. 33)

Essa consideração descreve a forma como o futebol é "trabalhado" no Brasil. É sempre visto esse jogo entre o passado e o futuro, essa rememoração das glórias passadas e o impulso de conquistar mais títulos. Por isso que se torna cada vez mais necessário analisar conteúdos jornalísticos de cunho esportivo, para a compreensão destas e de outras impressões transmitidas.

A partir de agora, faremos a análise do discurso contido na primeira de uma série de reportagens sobre os jogadores da seleção brasileira que disputaram a Copa do mundo na Rússia em 2018. A reportagem, construída pelo jornalista Tino Marcos, foi veiculada no Jornal Nacional, no dia 15 de maio de 2018, um mês antes do início da Copa. A reportagem trata sobre o atacante Neymar Júnior, camisa 10 da seleção brasileira.

Quando se observa o contexto, percebe-se que a reportagem foi transmitida no jornal de maior audiência da emissora, que é a segunda maior emissora do mundo em índices de audiência ${ }^{35}$. Quem anuncia o produto é a jornalista Renata Vasconcellos que diz ao telespectador que a matéria que será exibida a seguir compõe uma série e que o personagem do qual ela trata é o "maior astro do time".

Percebe-se, ao fundo, uma imagem para exemplificar a matéria que contém as costas das camisas usadas pelos jogadores da seleção. Uma das camisas dispostas na parte central da imagem, é a de número 10, utilizada pelo jogador Neymar Júnior.

${ }^{35}$ Segundo site organizacional que apura ranking nacional. https://top10mais.org/top-10-maiores-emissoras-tvmundo/ 
No que se refere aos sujeitos predominantes no discurso, considerou-se comunicante (EUc), o sujeito enunciador (EUe) e o sujeito destinatário (TUd), e o sujeito interpretante (TUi). Com o seguinte quadro é possível compreender melhor a situação de comunicação na qual os sujeitos do discurso estão inseridos:

Quadro 1 - Sujeitos do discurso

\begin{tabular}{|l|l|}
\hline \multicolumn{1}{|c|}{ SUJEITOS } & \multicolumn{1}{c|}{ DISCURSO } \\
\hline EUc & $\begin{array}{l}\text { Tino Marcos. Repórter da Rede Globo de te- } \\
\text { levisão, experiente no jornalismo televisivo. } \\
\text { Maior emissora do Brasil. }\end{array}$ \\
\hline EUe & Fã de futebol, ufanista, narrador participante. \\
\hline TUi & $\begin{array}{l}\text { Telespectadores do Jornal Nacional, em sua } \\
\text { maioria das classes C,D e E, adultos, homens, } \\
\text { trabalhadores }\end{array}$ \\
\hline TUd & Torcedores da seleção brasileira de futebol. \\
\hline
\end{tabular}

Fonte: autora (2019)

$\mathrm{Na}$ reportagem aqui analisada, três principais pessoas têm voz durante os onze minutos de produção. O repórter, na maior parte do tempo, o próprio Neymar que conta sua história e suas impressões sobre a carreira e a irmã do jogador que também traça suas impressões sobre a vida e carreira do irmão.

Para entendermos melhor o discurso contido na reportagem o quadro a seguir contém alguns trechos das falas dos sujeitos acima descritos:

Quadro 2: falas dos personagens

\begin{tabular}{|l|l|}
\hline \multirow{3}{*}{ NEYMAR } & $\begin{array}{l}\text { - [sobre os amigos] "eu gosto porque consigo me tornar normal perto deles" } \\
\text { - "Quando eu faço alguma coisa ela multiplica ou triplica, nem Deus agradou a } \\
\text { todos imagina eu" }\end{array}$ \\
& $\begin{array}{l}\text {-"Espero ser campeão mundial pelo meu país [...] que é meu objetivo maior" } \\
\text { - [em relação aos dribles] - "É o que me faz diferente" }\end{array}$ \\
\hline & $\begin{array}{l}\text { - "Eu e meu irmão a gente tem uma coisa em comum, a gente não gosta de } \\
\text { ficar sozinho" } \\
\text { IRMÃ DO }\end{array}$ \\
JOGADOR & $\begin{array}{l}\text { e pedia perdão por não ter protegido meu irmão" } \\
\text {-"Eu falava mãe, você não fez um menino, você fez uma máquina, porque esse } \\
\text { menino é de outro mundo" }\end{array}$ \\
\hline REPÓRTER & - "Neymar. Duas sílabas, seis letras que o mundo do futebol aprendeu a ecoar" \\
\hline
\end{tabular}




\begin{tabular}{|l|l|}
\hline - "Espera-se muito de Neymar, desde sempre" \\
- "Viu da cama os 7 a 1" \\
- "A maior jóia do Santos desde Pelé" \\
- "Em 4 anos, 10 títulos, incluindo uma liga dos campeões da Europa e um \\
mundial de clubes" \\
- "Até se tornar o jogador mais caro do mundo" \\
- "Foram várias atuações no "padrão Neymar de futebol" \\
- "São oito anos de protagonismo com essa camisa [...] já é o $5^{\circ}$ maior artilheiro \\
da história da seleção"
\end{tabular}

Fonte: autora (2019)

É possível observar nas falas do jogador durante a reportagem, um discurso que evidencia seu próprio potencial como atacante, mas tenta conceber uma imagem que sua carreira é construída dia após dia, como uma saga, que iniciou de forma simples e alcançou grandes proporções.

Pode-se observar que em suas falas ele sempre remete aos prazeres da vida paralela ao futebol, como estar com amigos e família, coisas que o fazem feliz e que, apesar da fama, ele é uma pessoa simples.

Nas falas da irmã esse discurso é reforçado. Ora ela enaltece as características do irmão ao dizer que ele "é de outro mundo", ora assimila a ele características simples como não gostar de estar sozinho. Essa relação entre 'um jogador exemplar' e 'um garoto simples' permeia as falas dessa personagem.

Na construção narrativa do repórter, mais uma vez, essas questões são observadas. São diversos os momentos em que o talento de Neymar é evidenciado. Nas informações da quantidade de títulos adquiridos, das transações financeiras envolvendo o jogador, da quantidade de anos em que "protagoniza" os jogos da seleção, do alto "padrão" criado pelo atacante que é perceptível em sua forma de jogar.

Além disso, é evidenciado o fato de que Neymar se tornou conhecido por fazer história em grandes clubes, não só brasileiros, mas também na própria seleção, se tornando o $5^{\circ}$ maior artilheiro da melhor seleção do mundo. Ainda segundo o repórter, o nome do jogador, por conta desses feitos, tem sido constantemente 'ecoado' por todo o mundo. 
É interessante observar que todas essas considerações feitas por parte do repórter se utilizaram de raros adjetivos. A construção da narrativa se dava mais de forma descritiva do que opinativa, mas com algumas observações próprias do repórter que constrói um discurso específico.

O contrato de comunicação dessa reportagem coloca de um lado o Jornal Nacional, personificado na figura do repórter Tino Marcos e, de outro, o telespectador, onde o sujeito produtor tem a atribuição de informar e o destinatário de ser informado. Nesta reportagem, Tino Marcos exerce a função de emitir as informações disponibilizadas em suas pesquisas e produção da reportagem sobre o jogador, mas, além disso, emite algumas opiniões que ele não trata como próprias, e sim como algo de consentimento mundial.

Além do discurso expresso pela linguagem verbal, é necessário pontuar o discurso contido nas imagens, nos recursos visuais e sonoros. Nos momentos em que são mostradas as imagens dos dribles e das jogadas de Neymar nas partidas que participou, é projetada uma arte, de uma sala de cinema, onde essas jogadas são transmitidas em um grande telão. Acompanhando essas imagens, as músicas ao fundo sempre em tom de "triunfo".

O recurso slow motion é bastante utilizado para mostrar as jogadas feitas por ele, e também para mostrar os momentos em que ele estava sobre os olhares dos fotógrafos. No final da reportagem, o protagonismo do jogador é ainda mais evidenciado quando, em uma imagem editada, colocam um holofote em cima dele, enquanto ele caminha para bater o pênalti que daria a medalha de ouro à seleção olímpica de 2016. Depois do gol, todos correm até ele para comemorar o título e, mais uma vez, uma música "triunfante" é observada ao fundo.

Percebeu-se ainda que a opção da TV Globo em escolher o repórter Tino Marcos para a construção não só dessa reportagem, mas de toda a série, pretende estabelecer um contrato de confiança com o telespectador, visto que o repórter tem uma extensa carreira no jornalismo esportivo, tendo participado da cobertura de mais de seis copas do mundo.

Percebeu-se, na reportagem analisada uma construção narrativa semelhante a 'saga do herói’ comumente encontrada nos gibis, filmes e produtos audiovisuais. Isso é não só 
marcado no discurso dos atores de fala como nos recursos visuais, sonoros, a forma de narrar do repórter e pela conjuntura da série que a reportagem está inserida. A descrição das características do personagem assimilada a sua simplicidade, que segue colecionando aos poucos suas vitórias e enfim é considerado realmente como um grande herói e muito parecida com a narrativa construída na reportagem.

Ao pesquisar sobre as mitologias políticas, Girardet (1987) afirma que uma das mitologias mais fortes ligada à construção dos Estados nacionais e do sentimento de nacionalidade é a do salvador - ou herói se assim o quisermos - , pois ele serve para ressaltar não apenas a sua glória, mas a glória do país e das demais pessoas pertencentes aquele país. Como ele afirma, o herói é "alguém capaz de reverter a situação vigente, tida como má, e instaurar uma nova era de paz e prosperidade. Ou melhor: não instaurar, mas conduzir o grupo - via de regra, a nação - ao futuro glorioso que de antemão lhe estava reservado” (1987, p. 20).

O repórter emprega estratégias discursivas como o convencimento (quando descreve os títulos do atleta, afirma que ele é tão bom quanto Pelé que é considerado "o rei do futebol brasileiro), sem necessariamente utilizar uma grande quantidade de adjetivos para transmitir essa noção e ainda ressalta características pessoais dele que buscam estabelecer essa relação de aproximação e credibilidade com o público, sempre apelando para as emoções e tratando sobre impressões tidas por ele, como sendo impressões comuns a todas as pessoas.

Cabe relembrar que neste caso, o sujeito comunicante é personificado na figura do repórter Tino Marcos, mas as impressões por ele partilhadas representam toda uma linha editorial do jornal, emissora, passando pelas funções de diversos jornalistas envolvidos direta e indiretamente com o conteúdo veiculado no jornal. É importante salientar que essa é uma prática comum do Jornal Nacional, exibir esse modelo de reportagem exaltando os brasileiros que se destacam em grandes eventos esportivos, como por exemplo, as olimpíadas. 
Por fim, vale ressaltar que a colaboração da presente pesquisa pode trazer novas perspectivas em torno das discussões do futebol, sua relação com a identidade nacional e como isso está atrelado aos discursos produzidos pelos meios de comunicação. Novas pesquisas dentro dessa perspectiva com certeza devem colaborar e muito para a compreensão da sociedade.

\title{
TELEVISIVE SPEECH ABOUT NEYMAR JUNIOR AND BRAZILIAN SOCCER
}

\begin{abstract}
This article aims to understand the speech contained in a report about the Brazilian national team player, Neymar Júnior and how he is evidenced in the narrative construction. It discusses how national identity is built and how football has been a fundamental element in the construction of Brazilian national identity. Finally, it is analyzed, in light of the theory of discourse analysis proposed by Charaudeau (2008), the report about the attacker, shown in the National Journal of Rede Globo television. The report is part of a series entitled "Profiles", broadcast in August 2018, which aimed to introduce the Brazilian national team players who played in the 2018 World Cup in Russia. The objective is to unveil the strategies used by the author in the text in the construction of a discourse about the attacker. It is concluded that the discourse constructed in the report relates the player's image to that of a national hero.
\end{abstract}

KEYWORDS: Speech; Soccer; National identity; Journalism; Narrative.

\section{REFERÊNCIAS}

AVRELLA, Bárbara; CARVALHO, Cristiane Mafacioli. Ricardo Boechat: uma análise do discurso do jornalista no rádio e na televisão. Estudos do jornalismo e mídia, Santa Catarina, n. 1, mai. 2018.

BELTRÃO, Luiz. Iniciação à filosofia do jornalismo. Rio de Janeiro: Livraria Agir Editora, 1960.

CHARAUDEAU, Patrick. Linguagem e Discurso: modos de organização. Tradução de

Angela Corrêa e Ida Lúcia Machado. São Paulo: Contexto, 2008.

; MAINGUENEAU, Dominique. Dicionário de análise do discurso. Tradução

de Fabiana Komesu. São Paulo: Contexto, 2004.

GIRARDET, R. Mitos e mitologias políticas. São Paulo: Companhia das Letras, 1987.

HALL, Stuart. A identidade cultural na pós-modernidade. Rio de Janeiro: Lamparina, 2015. 
SODRÉ, Muniz; FERRARI, Maria Helena. Técnica de reportagem: notas sobre a narrativa jornalística. Rio de Janeiro: Summus, 1986.

KELLNER, D. A cultura da mídia e o triunfo do espetáculo. Trad. de Rosemary Duarte, Líbero, ano VI, v. 6, n. 11, 2006.

Recebido em: 31/08/2019.

Aprovado em: 02/01/2020. 